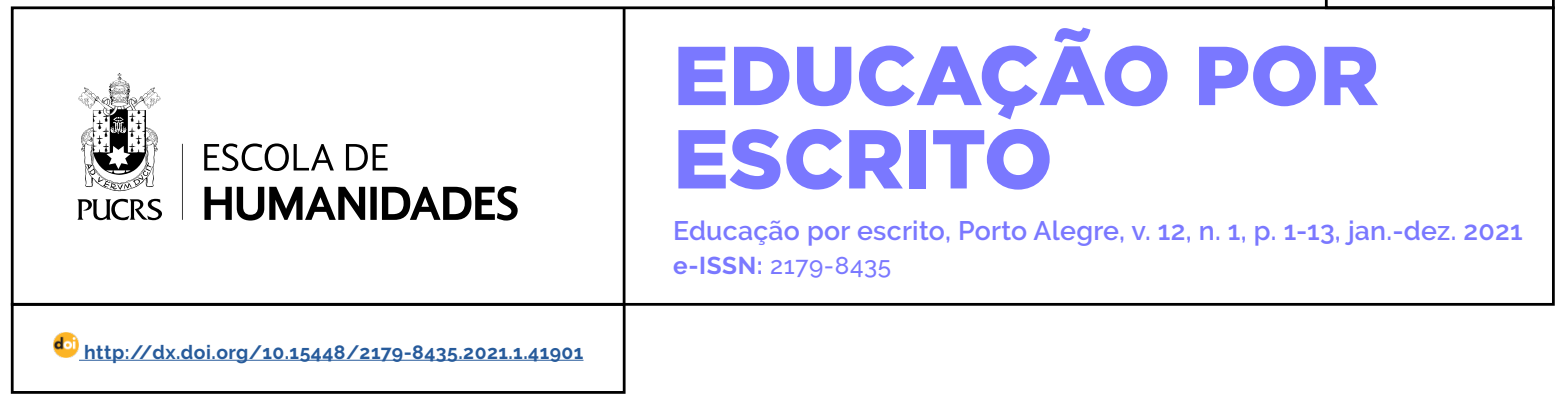

SEÇÃO: A FORMAÇÃO DE PROFESSORES E A EDUCAÇÃO INCLUSIVA: AVANÇOS, DESAFIOS E PERSPECTIVAS

\title{
Atendimento Educacional Especializado para estudantes com transtorno do espectro autista na Associação Pestalozzi de Goiânia - Unidade Renascer
}

\author{
Specialized Educational Service for students with autism spectrum disorder at \\ Associação Pestalozzi de Goiânia - Renascer Unit
}

\author{
Márcia Sacramento \\ Rocha $^{1}$ \\ orcid.org/0000-0002-2193-4369 \\ marciasacramentorocha@gmail. \\ com
}

\section{Ana Flávia Teodoro de Mendonça Oliveira ${ }^{1}$ orcid.org/0000-0002-4357-6558 anaflavia1973@ufg.br}

\section{Michell Pedruzzi \\ Mendes Araújo ${ }^{1}$}

orcid.org/0000-0003-4596-5386 michellpedruzzi@ufg.br

Recebido em: 30/09/2021. Aprovado em: $12 / 11 / 2021$. Publicado em: 22/11/2021.
Resumo: Este estudo, de cunho qualitativo, objetiva compreender como se dá o Atendimento Educacional Especializado (AEE) para alunos com Transtorno do Espectro do Autismo (TEA) na Associação Pestalozzi de Goiânia - Unidade Renascer. Participou da pesquisa uma professora do Atendimento Educacional Especializado da referida instituição, que trabalha com alunos com TEA. Para coleta de dados, foram aplicadas entrevistas semiestruturadas e realizada uma análise documental do Projeto Político Pedagógico da instituição. Os dados foram transcritos e analisados a partir da técnica de análise de conteúdo de Bardin (2011). Os resultados obtidos desvelam questões importantes sobre os objetivos do AEE a serem alcançados pelas crianças com autismo, bem como aos planos de intervenções desenvolvidos tomando como base suas necessidades. Além de descrever a organização dos atendimentos e as práticas pedagógicas desenvolvidas pela docente preconizadas pela metodologia TEACCH (Tratamento e Educação para Autistas e Crianças com Limitações), buscou-se compreender a adequação do comportamento e o processo de socialização para favorecer a construção da autonomia, de acordo com suas particularidades. Ademais, a presente investigação evidencia a relação entre professor do AEE, professor da rede regular de ensino e familia da criança com TEA, e também os materiais pedagógicos e recursos multifuncionais utilizados nos atendimentos. Por fim, conclui-se que o trabalho pedagógico desenvolvido pela docente na sala do AEE está em consonância com os documentos nacionais que preconizam a inclusão, portanto decorrem da tentativa de romper as barreiras impeditivas à construção do conhecimento e à ocorrência de relações dialógicas e alteritárias entre os indivíduos.

Palavras-chave: Atendimento Educacional Especializado. Transtorno do Espectro Autista. Inclusão escolar. Sala de Recursos Multifuncionais.

Abstract: This qualitative study aims to understand how Specialized Educational Care (AEE) is provided for students with Autism Spectrum Disorder (ASD) at Associação Pestalozzi de Goiânia - Renascer Unit. A professor from the Specialized Educational Service of the aforementioned institution, who works with students with ASD, participated in the research. For data collection, semi-structured interviews were applied and a documental analysis of the institution's Pedagogical Political Project was carried out. Data were transcribed and analyzed using Bardin's (2011) content analysis technique. The results obtained reveal important questions about the AEE objectives to be achieved by children with autism, as

\section{(c) (i)}

Artigo está licenciado sob forma de uma licença Creative Commons Atribuição 4.0 Internacional. 
well as the intervention plans developed based on their needs. In addition to describing the organization of care and the pedagogical practices developed by the teacher recommended by the TEACCH methodology (Treatment and Education for Autists and Children with Limitations), we sought to understand the adequacy of behavior and the socialization process to favor the construction of autonomy, according to its particularities. Furthermore, the present investigation highlights the relationship between the AEE teacher, the regular school teacher and the family of the child with ASD, as well as the pedagogical materials and multifunctional resources used in the care. Finally, it is concluded that the pedagogical work developed by the teacher in the AEE room is in line with the national documents that advocate inclusion, therefore, they result from the attempt to break the barriers that impede the construction of knowledge and the occurrence of dialogical and alterity relations between individuals.

Keywords: Specialized Educational Service. Autistic Spectrum Disorder. School inclusion. Multifunctional Resource Room.

\section{Introdução}

A educação inclusiva contrapõe-se a toda e qualquer formar de exclusão, partindo do pressuposto de que todas as pessoas têm direito a uma educação de qualidade e a uma educação que considere as necessidades e especificidades dos sujeitos, garantindo o seu desenvolvimento pleno em condições de equidade. Entretanto, há de se considerar que a educação inclusiva possibilitou avanços no que se refere à educação das pessoas com deficiência, mas, por outro lado, é preciso avançar no que diz respeito à inclusão dos estudantes com Transtorno do Espectro Autista (TEA) (OLIVEIRA, COSTA; SILVA, 2019).

Nesse sentido, Cruz (2014) ressalta que o processo educacional dos sujeitos com Transtorno do Espectro Autista (TEA) mostra-se muito vulnerável, uma vez que a escola, em geral, não está preparada e os profissionais não estão capacitados para receber e acolher esses alunos e, como consequência, o processo de inclusão educacional não acontece de maneira plena. Em face do exposto, a autora afirma que os estudantes com TEA "[...] geralmente recebem investimentos pautados em cuidados excessivos que levam a estereótipos e, em grande parte das vezes, constroem condições desfavoráveis e empobrecidas que tendem a não lhes propiciar experiências sociais significativas" (CRUZ, 2014, p. 59).
Nesse contexto, entendemos que uma das condições preconizadas para que o estudante autista permaneça incluso em sala de aula regular é o suporte oferecido pela educação especial, por meio do Atendimento Educacional Especializado (AEE). A esse respeito, a Política Nacional de Educação Especial na perspectiva da Educação Inclusiva (PNEE) (BRASIL, 2008b) destaca a importância do atendimento educacional especializado, visando a eliminação de barreiras que impedem ou dificultam a inclusão dos estudantes público-alvo da educação especial no sistema regular de ensino. Nesse sentido, o referido documento preceitua que:

O atendimento educacional especializado identifica, elabora e organiza recursos pedagógicos e de acessibilidade que eliminem as barreiras para a plena participação dos alunos, considerando as suas necessidades especificas. As atividades desenvolvidas no atendimento educacional especializado diferenciam-se daquelas realizadas na sala de aula comum, não sendo substitutivas à escolarização (BRASIL, 2008b).

Tendo em vista o direito das pessoas com autismo a atendimentos e serviços que contemplem as suas necessidades e especificidades, destaca-se, na cidade de Goiânia-GO, um centro de referência no atendimento educacional especializado para esses estudantes, a Associação Pestalozzi de Goiânia - Unidade Renascer. A referida instituição oferece aos educandos com deficiência intelectual, deficiências múltiplas (deficiência intelectual associada a deficiências neuro-motoras), Transtornos do Espectro Autista (TEA) ou hipótese diagnóstica de autismo, o Atendimento Educacional Especializado (AEE), o Ensino Especializado (EE) e Programa de Apoio à Inclusão, quando solicitado (GOIÂNIA, 2019).

Nessa perspectiva, considerando a importância da instituição Pestalozzi para o atendimento das crianças com autismo, o presente artigo objetiva compreender como se dá o Atendimento Educacional Especializado (AEE) para alunos com Transtorno do Espectro do Autismo (TEA) na Associação Pestalozzi de Goiânia - Unidade Renascer. 


\section{Caminho metodológico}

Esta pesquisa se configura, quanto à natureza, como qualitativa, e, quanto aos fins, como exploratória. Para recolha dos dados utilizamos a pesquisa documental e a entrevista semiestruturada com uma professora do Atendimento Educacional Especializado (AEE), que atende as crianças com autismo na instituição. No que se refere às fontes documentais, utilizamos o Projeto Político Pedagógico disponibilizado pela instituição.

O roteiro de entrevistas contemplou as seguintes questões: como é realizado o Atendimento Educacional Especializado com estudantes com autismo (explicar detalhadamente: quantas vezes por semana, em grupo ou individual, orientação para os professores, orientação para familia, enfim, como funciona)? como é a relação do professor da classe comum com vocês que são professoras do AEE? Quais são os objetivos pedagógicos do AEE para os estudantes com autismo?

Os documentos e as entrevistas realizadas com as professoras do AEE, transcritas na integra, foram analisados tendo por procedimento a Análise de Conteúdo, na perspectiva de Bardin (2011). Para a análise categorial da entrevista, se utilizou principalmente da análise temática, que, por sua vez, segundo a autora, "consiste em descobrir os núcleos de sentido que compõem a comunicação e cuja presença ou frequência de aparição pode significar algo para o objetivo analitico escolhido" (BARDIN, 2011, p. 131).

No processo de desmembramento do texto (entrevistas e documentos), foram desencadeadas unidades de registro (que consistem em unidades de significação do texto e de registro) para o reagrupamento das categorias temáticas por semelhança, podendo apresentar dimensões e natureza variáveis, e consistindo-se em frases, palavras ou expressões. As expressões, segundo expressa Bardin (2011), carregam em si os pontos-chave de significação para o sujeito a respeito da experiência estudada. Além disso, as unidades de registro revelam ao pesquisador 0 significado e sentido do ponto estudado.

Quanto aos aspectos éticos da pesquisa, inicialmente, foi solicitado à Gerência de Educação
Especial e à Associação Pestalozzi de Goiânia Unidade Renascer a autorização para a realização da recolha de dados. Com a autorização do referido órgão, a presente pesquisa foi encaminhada e aprovada pelo Comitê de Ética da Universidade Federal de Goiás, com base no parecer número CAAE: 92468918.3.0000.5083.

\section{Resultados e discussão}

No Quadro 1 são apresentadas as cinco categorias estabelecidas para análise das respostas dos participantes e os assuntos tratados em cada uma delas.

Quadro 1 - Categorias de análise e os assuntos tratados

\begin{tabular}{|l|l|}
\hline $\begin{array}{l}\text { Categorias de } \\
\text { Análise }\end{array}$ & $\begin{array}{l}\text { Assuntos tratados em cada } \\
\text { categoria }\end{array}$ \\
\hline $\begin{array}{l}\text { 1. Objetivos, } \\
\text { Organização e } \\
\text { funcionamen- } \\
\text { to do AEE }\end{array}$ & $\begin{array}{l}\text { Atendimentos } \\
\text { Duração } \\
\text { Formas de agrupamento }\end{array}$ \\
\hline $\begin{array}{l}\text { 3. A interven- } \\
\text { ção Pedagógi- } \\
\text { ca no Autismo }\end{array}$ & $\begin{array}{l}\text { - Intervenção na Linguagem } \\
\text { trabalho com o estudante com } \\
\text { tos autolesivos, nas estereotipias } \\
\text { e na fixação por determinados } \\
\text { objetos }\end{array}$ \\
\hline $\begin{array}{l}\text { 4. Parceria en- } \\
\text { tre o AEE e o } \\
\text { ensino regular }\end{array}$ & $\begin{array}{l}\text { - Orientação professor espe- } \\
\text { cialista - professora da classe } \\
\text { comum } \\
\text { - Dificuldades } \\
\text { - Parcerias }\end{array}$ \\
\hline $\begin{array}{l}\text { 5. Parceria } \\
\text { entre o AEE e } \\
\text { a familia }\end{array}$ & $\begin{array}{l}\text { - Orientação } \\
\text {-Dificuldades } \\
\text { - Parcerias }\end{array}$ \\
\hline
\end{tabular}

Fonte: Elaborado pelos autores (2021).

\subsection{Objetivos, organização e funcionamento do Atendimento Educacional Especializado para alunos com Transtorno do Espectro Autista na associação Pestalozzi de Goiânia - Unidade Renascer}

No projeto Político Pedagógico da instituição, datado de 2019, consta que o Atendimento Educacional Especializado foi implantando no segundo semestre do ano de 2005. O documento 
ressalta ainda que, para manter os atendimentos na área da educação, a Instituição é conveniada com a Secretaria Municipal e Estadual da Educação, que disponibiliza pedagogos e profissionais administrativos.

$\mathrm{Na}$ área da saúde, mantém convênio com o Sistema Único de Saúde (SUS), onde a Pestalozzi recebe mediante contrato firmado com a Secretaria Municipal de Saúde profissionais que integram os setores de fonoaudiologia, fisioterapia, psicologia, neuropediatria, fisiatria, enfermagem, terapia ocupacional, odontologia, audiologia clínica e assistência social (GOIÂNIA, 2019).

Ademais, a instituição mantém convênios com as Secretarias Municipais de Educação e Esporte e Secretaria de Saúde de Goiânia, funcionando como campo de estágio supervisionado com a Universidade Estadual de Goiás (ESEFEGO) Curso de Educação Física; Universidade Federal de Goiás (UFG) - Cursos de Pedagogia e Musicoterapia. (GOIÂNIA, 2019, p. 12).

O documento sinaliza também que no Programa de Atendimento Educacional Especializado para a educação infantil as crianças (de zero a cinco anos e 11 meses) recebem atendimento duas vezes por semana no contraturno. O referido atendimento tem como foco a "Estimulação Essencial", objetivando oportunizar o desenvolvimento dessas crianças, sobretudo, em relação as funções motoras, cognitivas, sociais e linguísticas.

No Programa de Atendimento Educacional Especializado, modalidade Educação Infantil, as crianças com Transtorno do Espectro Autista (TEA), de zero a cinco anos e 11 meses recebem atendimento duas vezes por semana no contraturno. O documento preconiza que as crianças podem ser atendidas de forma individual e/ou em grupos constituido por dois a quatro elementos, com duração de trinta e cinco a quarenta minutos, duas vezes por semana. O objetivo desse atendimento é possibilitar ao educando, o desenvolvimento das funções cognitivas, motoras e sociais, bem como, o crescimento integral das três faculdades: pensar, sentir e querer por meio de atividades lúdicas em uma ação conjunta entre criança, familia e instituição, contribuindo para a construção do conhecimento e melhoraria no desempenho social.

O Programa de Atendimento Educacional Especializado na modalidade do Ensino Fundamental é destinado para crianças de seis anos a 13 anos e 11 meses, podendo ser atendidos de forma individual e/ou em grupos de dois a quatro elementos, com duração de 35 a 40 minutos, duas vezes por semana. 0 objetivo desse atendimento é oferecer aos educandos matriculados na rede municipal de ensino condições para que sua inclusão escolar e social aconteça de forma plena, portanto, possibilita aos educandos o desenvolvimento da capacidade de olhar e escutar, questionar, verbalizar, descobrir e se perceber.

Outrossim, no Projeto Político Pedagógico da Associação Pestalozzi de Goiânia - Unidade Renascer- estão enumeradas as atribuições do professor de AEE, a saber:

1- Elaborar, executar e avaliar o Plano de AEE do aluno, contemplando: a identificação das habilidades e necessidades educacionais especificas dos educandos, a definição e a organização das estratégias, serviços e recursos pedagógicos e de acessibilidade; o tipo de atendimento conforme as necessidades educacionais específicas dos educandos; o cronograma do atendimento e a carga horária, individual ou em pequenos grupos;

2- Programar, acompanhar e avaliar a funcionalidade e a aplicabilidade dos recursos pedagógicos e de acessibilidade no AEE, na sala de aula comum e nos demais ambientes da escola:

3- Produzir materiais didáticos e pedagógicos acessiveis, considerando as necessidades educacionais especificas dos alunos e os desafios que estes vivenciam no ensino comum, a partir dos objetivos e das atividades propostas no curriculo;

4- Estabelecer a articulação com os professores da sala de aula comum e com os demais profissionais de escola, visando a disponibilização dos serviços e recursos e o desenvolvimento de atividades para a participação e aprendizagem dos alunos nas atividades escolares; bem como as parcerias com as áreas intersetoriais;

5- Orientar os demais professores e as familias sobre os recursos pedagógicos e de acessibilidade utilizados pelo aluno de forma a ampliar suas habilidades, promovendo sua autonomia e participação;

6- Desenvolver atividades próprias do AEE, de acordo com as necessidades educacionais específicas dos alunos; ensino da Língua 6- 
Portuguesa escrita para alunos surdez; ensino da Comunicação Aumentativa e Alternativa - CAA; ensino do sistema Braille; do uso do soroban e das técnicas para a orientação e mobilidade para alunos cegos; ensino da informática acessivel e do uso de recursos de Tecnologia Assistiva- TA; ensino de atividades de vida autônoma e social; orientação de atividades de enriquecimento curricular para as altas habilidades/ superdotação; e promoção de atividades para o desenvolvimento das funções mentais superiores (GOIÂNIA, 2019, p. 30-31).

No Projeto Político Pedagógico da Instituição destaca-se que a entrada de novos educandos na Unidade acontece de acordo com a necessidade do aluno. Sendo assim, os estudantes podem ser encaminhados para o Atendimento Educacional Especializado (AEE) ou para o Ensino Especial (EE). O documento preceitua também que os educandos da rede municipal de educação são encaminhados para o programa de Atendimento Educacional Especializado, pelas Coordenadorias Regionais de Educação (CREs) por meio do parecer emitido pela Equipe Multidisciplinar ou por meio dos relatórios descritivos com apresentação da queixa da escola acerca da dificuldade do educando e conta com 270 vagas.

No que concerne ao trabalho desenvolvido, a professora (informação verbal) destaca que o AEE não é um trabalho de reforço escolar. A respeito disso, menciona:

Os conteúdos lá da escola, dependendo, as nossas crianças não acompanham. A gente deixa isso bem claro para a escola que nosso atendimento não é um reforço. Depois, vamos supor, eu entendo que, se há crianças aqui que estão na fase da leitura e escrita, não há impedimento para eu trabalhar esses processos. [...] Eu vou facilitar, nós somos facilitadores. Por isso que nós somos apoio, então o que faremos é trabalhar com nossas crianças, com nossos educandos aqui, pra eles entenderem o que é esse livro lá na escola, o que são esses livrinhos literários, etc. A maioria das nossas crianças, antes de passar pelo CAE Renascer, rasga os livros e não consegue sentar na rodinha de conversa. Portanto, atuamos no AEE de maneira a facilitar o trabalho dos professores lá na escola regular (Professora do AEE, informação verbal).
De acordo com o Decreto n० 7.611 (BRASIL, 2011, p. 2), o Atendimento Educacional Especializado (AEE) deve ter como objetivo "fomentar o desenvolvimento de recursos didáticos e pedagógicos que eliminem barreiras no processo de ensino e aprendizagem".

Nessa perspectiva, a Política Nacional de Educação Especial na Perspectiva da Educação Inclusiva (BRASIL, 2008b) reitera que "as atividades desenvolvidas no Atendimento Educacional Especializado se diferenciam daquelas realizadas na sala de aula comum, não sendo substitutivas à escolarização" (BRASIL, 2008b, p. 11).

\subsection{A intervenção Pedagógica no Autismo}

Nesta categoria trazemos à tona os pressupostos que fundamentam a abordagem pedagógica no Atendimento Educacional Especializado para os estudantes com Transtorno do Espectro Autista. Assim, analisamos a abordagem metodológica utilizada, e a forma de intervenção nos aspectos linguísticos e comportamentais.

\subsubsection{A abordagem metodológica TEACCH}

De acordo com a professora do $\mathrm{AEE}^{2}$ (informação verbal), a intervenção pedagógica realizada com a criança autista objetiva trabalhar três áreas importantes que se encontram deficitárias. vejamo-las:

No AEE trabalhamos a adequação do comportamento das crianças autistas. Dentro dessa adequação de comportamento abrangemos todas as áreas em que a mesma apresenta dificuldades. A maior dificuldade dos autistas é em relação a interação social, ao comportamento e à comunicação. Então focamos nesses três aspectos para realizar a intervenção pedagógica (Professora do AEE, informação verbal).

Acerca do trabalho com as crianças que possuem autismo no AEE, toda a equipe multidisciplinar utiliza a abordagem TEACCH (Treatment and Education of Autistic and related Communication-handicapped Children), como se pode observar no excerto extraído do Projeto Político

2 Depoimento da professora do AEE concedido aos pesquisadores Rocha, Oliveira e Araújo durante a realização da entrevista, na cidade de Goiânia, GO, Brasil, no dia 19, setembro do ano 2019. Salientamos que, ao decorrer dos resultados, são apresentados relatos dessa mesma docente- professora do AEE - oriundos das entrevistas realizadas na mesma localidade, mês e ano. 
Pedagógico da Instituição:

A equipe multiprofissional é composta de pedagogos, professor de educação física, fonoaudiólogo, musicoterapeuta, psicólogo, atuando numa abordagem interdisciplinar e/ou transdisciplinar, utilizando a metodologia TEACCH como suporte teórico à proposição das intervenções (GOIÂNIA, 2019, p. 131).

A docente (informação verbal) sublinha ainda que um das justificativas para o uso da abordagem TEACCH deve-se ao fato de que a mesma preconiza a organização do ambiente, favorecendo a organização da rotina e potencializando, consequentemente, a estruturação da própria criança. Completando, a professora ressalta:

Sobre a abordagem, nós fizemos todo um estudo e entendemos que a metodologia TEACCH é a que favorece mais a criança autista. Não somos contra outros métodos e temos a liberdade de usar outras abordagens, mas o nosso CAE-Renascer acredita que o TEACCH é uma abordagem mais acessivel. Essa abordagem trabalha com a qualidade de vida, promovendo a organização do ambiente e da rotina da criança, o que acaba facilitando a compreensão dessa criança autista. [...] Quando a criança chega na sala de AEE é muito importante que este ambiente esteja organizado para recebê-la. Não sei se vocês observaram, mas aqui na sala, quando a familia chega, a questão mais importante é o ambiente estar estruturado, organizado. Essa rotina é importante, porque crianças com TEA precisam dessa rotina. Afinal, elas aprendem melhor quando há uma manutenção da rotina e da previsibilidade (Professora do AEE, informação verbal).

A professora (informação verbal) observa ainda que a criança autista pode desestruturar-se quando a sala não está organizada da maneira habitual. De acordo com a professora, a abordagem TEACCH propicia tanto a organização quanto o desenvolvimento da autonomia da criança.

Quando a criança não encontrar uma rotina, ela acaba se desestruturando. Por exemplo, ela entra na sala e, ao não ter pra onde ir, ela se perde, e aí é em que a maioria das nossas crianças se desestrutura. Porque ele chega, não é recebido, e não sabe pra onde ele vai. Então a metodologia, o método TEACCH, preconiza isso. Pra ajudar essa organização do ambiente, o método também facilita o nosso trabalho, e a qualidade de vida, pois trabalha a autonomia da criança (Professora do AEE, informação verbal).
No discurso de Tammet (2007), personalidade conhecida mundialmente que apresenta autismo, desvela-se que a imprevisibilidade e a mudança podem gerar sérios problemas para as pessoas com o transtorno. Sobre a mudança de rotina e os incômodos provenientes dessa situação, o sujeito com autismo relata que:

Sentimentos de alta ansiedade eram comuns
no horário da sala da escola. Eu ficava nervo-
so quando um evento escolar do qual todos
deveriam participar era anunciado em cima
da hora, ou [sic] por mudanças nas rotinas nor-
mais da turma. A previsibilidade era importante
para mim, uma forma de me sentir no controle
de uma dada situação e de manter distante a
sensação de ansiedade, ao menos tempora-
riamente. Nunca me senti à vontade na escola
e raramente estava feliz, exceto quando me
deixavam sozinho para fazer minhas próprias
coisas. A forte sensação de ordem e rotina me
acalmava e muitas vezes [sicl eu me sentava no
chão do auditório de olhos fechados, balançan-
do levemente enquanto cantarolava para mim -
algo que eu costumava fazer quando me sentia
relaxado e contente (TAMMET, 2007, p. 28, 50).

Cabe ressaltar que o método TEACCH (Treatment and Education of Autistic and related Communication-handicapped Children) fundamenta-se em um trabalho centrado nos principios da:

[...] organização, rotina, tarefas estruturadas, material visualmente mediado, ensino das relações de causa e efeito, comunicação alternativa, espaços com suas funções, delimitações fisicas, eliminação de estimulos concorrentes e controle de comportamento (LEON; FONSECA, 2013 apud FONSECA; CIOLA, 2014, p. 15).

De forma análoga, Fonseca e Ciola (2014) consideram que o programa TEACCH organiza os espaços, materiais e atividades, ou seja, organiza o ambiente externo, para que a criança com autismo possa organizar-se internamente. Ademais, as autoras destacam que o ensino estruturado "inclui a utilização de uma rotina de trabalho individualizada, buscando compensar os déficits cognitivos, sensoriais, sociais, comunicacionais e comportamentais presentes no TEA e interferentes no desenvolvimento" (FONSECA; CIOLA, 2014, p. 20). 


\subsubsection{A intervenção pedagógica na \\ comunicação da criança com autismo}

No que se refere às questões de linguagem, a professora do AEE explicita que algumas crianças são verbais e outras não verbais. Ademais, deixa claro que os pais têm uma grande expectativa em relação ao desenvolvimento da fala de seus filhos. Sendo assim, a docente explicita que:

Eu atendo crianças verbais e não-verbais. Algumas crianças chegam ao atendimento e ainda não falam. Então, fazemos todo um trabalho para estimular essa linguagem. A familia quando chega já pergunta se a criança vai falar. Respondemos que o tempo é da criança e que faremos todo esforço e trabalharemos no sentido de fazer com que essa criança fale (Professora do AEE, informação verbal).

Nunes (2013) ressalta que, desde os primeiros meses de vida, é evidente, nas crianças com autismo, a presença de déficit no desenvolvimento da linguagem e nas habilidades comunicativas. A preferência por sons não verbais e o balbucio tardio são algumas características encontradas.

A docente enfatiza que para facilitar o processo de comunicação devem-se usar frases curtas e poucas palavras com as crianças. Além disso, ressalta a importância de respeitar o tempo de desenvolvimento delas, como constatamos abaixo:

Para conversar com as crianças autistas devemos usar poucas palavras. O que são essas poucas palavras? Para criança autista não funciona falar muito, pois ela guardará apenas a última palavra. Assim, o método TEACCH preconiza que devemos usar poucas palavras, palavras curtas, claras, firmes, objetivas e a previsibilidade. [...] Vocês podem me perguntar: com essas poucas palavras como fica essa linguagem, como fica essa comunicação da criança? Primeiramente tenho que respeitar o tempo da criança. Para trabalhar a linguagem também uso jogos concretos e, através deles, vou trabalhando a comunicação.

Nesse sentido, o referencial curricular "Saberes e práticas da inclusão: dificuldades acentuadas de aprendizagem, autismo" (BRASIL, 2004) afirma que a comunicação verbal é um dos problemas dos alunos com TEA. Por essa razão, o ensino não pode ser baseado apenas em explicações por meio da linguagem verbal:
A comunicação professor-aluno deve estabelecer-se de forma que o professor se dirija ao aluno com poucas palavras, claras e concretas; de preferência, no começo, apenas com substantivos. A linguagem deve avançar à medida que o professor tenha certeza de que a compreensão do seu aluno avançou (BRASIL, 2004, p. 29).

De acordo com a professora (informação verbal), a dificuldade na compreensão da linguagem, pode ser uma das causas de desregulação da criança.

As crianças com TEA, muitas vezes, se desestruturam porque não entendem o que você fala, por isso a importância de uma comunicação clara, firme e objetiva para que ela compreenda o que eu estou falando. Se eu falar, por exemplo, o nome da criança e pedir para ela pegar o jogo, elas fazem um determinado trabalho. Com certeza o excesso de comandos pode fazer com que a criança autista se confunda (Professora do AEE, informação verbal).

Para dirimir os problemas e evitar a desestruturação da criança autista, a docente avulta a importância de se trabalhar com a previsibilidade:

Trabalho com eles a previsibilidade. Por exemplo, quando eu vou falar pra ele o que vai acontecer, eu uso essa linguagem: Breno ${ }^{3}$ trabalhar com tia Dirce. Usamos a palavra trabalhar para diferenciar do brincar. Assim, antes de ele iniciar a atividade, eu tento dizer o que vai acontecer ou o que a criança irá fazer (Professora do AEE, informação verbal)

Nesse aspecto, Williams e Wright (2008) explicam que o comportamento da pessoa com autismo é dirigido por um desejo de previsibilidade, evitando a quebra de rotina. Conforme os estudiosos, a rotina ou ritual compulsivo pode ser caracterizado "por uma série de ações, geralmente executadas na mesma ordem e oriundas de uma intensa necessidade de repeti-las" (WILLIAMS; WRIGHT, 2008, p. 263).

Nessa perspectiva, concordamos com Oliveira, Costa e Silva (2019, p. 43), quando salientam que o professor deve conhecer as especificidades da linguagem dos alunos com TEA, buscando construir "subsidios para que se estabeleça, de maneira saudável, uma relação de comunicação com esses sujeitos, seja ela verbal, seja não 
verbal, já que ambas devem ser valorizadas e estimuladas no espaço escolar".

\subsubsection{A intervenção pedagógica nos comportamentos autolesivos, nas estereotipias e na fixação por determinados objetos}

Os comportamentos autolesivos, segundo a professora (informação verbal), não devem ser permitidos, sobretudo para que a criança não aprenda a se comunicar por meio da agressividade. Ademais, a docente destaca que utiliza algumas atividades específicas para acalmar essas crianças.

Quando vem a agressividade e comportamentos autolesivos, a gente não deixa, se não a criança vai aprender a se comunicar por meio da agressividade e, por isso, é preciso conter a criança. [...] Aqueles comportamentos autolesivos, ou seja, quando a criança se automutila, que chamamos de autoagressão, dependendo da criança, eu seguro na mão e uso o termo dodói, dizendo vai doer em você. Após a situação eu seguro nas mãos dele e falo, dodói, acabou, acalmar. Tudo isso deve ser falado devagar. Não pode ser falado muito rápido. É bem pausadamente que a gente fala, pois é o tempo de latência para a criança processar as informações, e, nesse contexto, vamos adequar esse comportamento. [...] As crianças chegam desestruturadas, ai eu deixo brincar com aquilo que ela gosta para acalmá-la. É preciso entender o que passa na cabeça da criança, portanto a linguagem tem que ser diferente. Além disso, uso a música para ajudar a acalmar. Faço um trabalho com texturas também, pois muitas crianças com TEA têm dificuldades com o toque físico (Professora do AEE, informação verbal).

As condutas autolesivas podem ser compreendidas como comportamentos autodirigidos que causam danos corporais, como "morder o corpo, bater a cabeça, puxar o cabelo, bater no rosto, pressionar o globo ocular, puxar as orelhas são alguns dos comportamentos autolesivos tipicamente descritos na literatura" (IWATA et al., 1982 apud SOUZA; NUNES, 2019, p. 9).

Attwood (2010) enfatiza que as pessoas autistas podem ter uma hipo ou hipersensibilidade à dor, com uma tendência maior a ser hipo do que hipersensiveis. Sendo assim, o autor assevera que a falta de reação ao desconforto, à dor e a altas temperaturas podem fazer com que muitas dessas crianças não tenham ou não desenvolvam noções de perigo.
Ademais, o autor explica que algumas experiências sensoriais e perceptivas podem causar grande desconforto na pessoa autista, gerando uma série de estratégias de adaptação para enfrentá-las e compensá-las. Attwood (2010) também sugere que escrever uma "História Social" sobre a dor pode ajudar a criança a sentir-se bem novamente e evitar consequências mais sérias. Outra sugestão do autor, é a criação de um termômetro de emoções que possibilite à criança comunicar a intensidade da dor.

As estereotipias ou os chamados "Stims", segundo a professora (informação verbal), não devem ser contidos, pois tem a função de autorregulação.

No caso das crianças autistas, è nas estereotipias que, muitas vezes, eles se acalmam. Então não é necessário conter as estereotipias, pois essas crianças estão apenas se autorregulando (Professora do AEE, informação verbal).

Quanto a esse aspecto, Attwood (2010) enfatiza que os membros da familia, os professores e os colegas não devem criticar ou ridicularizar a criança pelos seus movimentos ou sons involuntários. Ademais, orienta o professor no sentido de ser um modelo para a aceitação dos tiques, providenciando, se necessário, um tempo extra para a criança completar uma atividade, além de encorajar os outros colegas, a tentar ignorar os movimentos ou sons feitos pelo autista.

No que diz respeito à fixação por determinados objetos, a docente (informação verbal) explica que desenvolve um trabalho de orientação à familia.

\begin{abstract}
Orientamos as famílias a deixar a criança com um objeto que não seja bizarro, um objeto que esteja de acordo com a idade dela. Nós já tivemos crianças aqui que gostavam de garrafa pet, outras gostavam de Galinha Pintadinha. Então, se ele gosta de um objeto que a gente entende que não é adequado para a idade dele, orientamos a familia a usar outro objeto e a gente faz todo um trabalho para que ele tenha interesse naquele outro objeto, pra substituir o objeto bizarro. Ou seja, a gente transfere e canaliza pra outra coisa ou para outro objeto (Professora do AEE, informação verbal).
\end{abstract}

A professora (informação verbal) salienta que a fixação da criança por um determinado objeto pode causar muito sofrimento. Nesse sentido, 
a docente afirma que realiza um trabalho de orientação às famílias, como constatamos no excerto abaixo:

Quando uma criança tem uma fixação por um objeto, deixar esse objeto causa muito sofrimento. Nesses casos, orientamos as familias a deixar o objeto dentro da mochila ou deixar a criança segurá-lo por algum tempo, pois são objetos que acalmam. Orientamos os pais que deixem o objeto na mochila independente se a criança está bem ou não, e aí, caso aconteça qualquer desestruturação na rua ou em qualquer ambiente, a familia dá o comando, dizendo, BRINCAR, e ai a gente prefere que seja brinquedos (Professora do AEE, informação verbal).

Sobre a importância dos objetos para a pessoa com autismo, Maleval (2017, p. 152) sublinha que "a maioria dos clínicos e educadores está de acordo em considerar que a criança autista necessita amparar seu pensamento em elementos concretos que progressivamente the permitem organizá-lo".

Ademais, o autor complementa dizendo que as narrativas de muitos sujeitos autistas evidenciam ou convergem para o entendimento de que certos objetos são, para eles, de um auxilio precioso. A importância desses objetos pode ser constatada nos depoimentos da autista Williams (2012), como se pode observar nos excertos a seguir.

Na época da minha avó, eu recuperava os pedaços de lã colorida, as sobras de tricô e crochêe passava os dedos neles para poder dormir em segurança. Para mim, as pessoas que eu amava eram os objetos, e esses objetos (ou as coisas que eles evocavam) eram a minha proteção contra as coisas que eu não amava, isto é, as outras pessoas (WILLIAMS, 2012, p. 31).

[...] Adorava ler os anuários telefônicos. Encontrara uma combinação para telefonar gratuitamente a partir da cabine da esquina. Consultava sistematicamente o anuário, depois telefonava ao primeiro e ao último nome da lista de cada letra. Explicava àqueles que me atendiam que os havia chamado porque eles eram o primeiro $A$, o último $B$, etc. A maioria desligava. Alguns me mandavam parar. [...] $O$ importante era haver conseguido estabelecer uma comunicação com as pessoas a partir de coisas inanimadas. O anuário tornou essa sala de aula a mais impessoal e a mais cômoda como jamais encontrei outra. [...] Após ter-me apoiado sobre os objetos para me comunicar, utilizei-os para estabelecer laços afetivos (WILLIAMS, 2012, p. 88, 89).
Dessa forma, embora muitos profissionais e familiares considerem os objetos de apego dos sujeitos autistas como anomalias comportamentais, que precisam ser normalizadas ou extirpadas, os discursos dessas pessoas desvelam que tais objetos cumprem uma função e tem importância fundamental para suas vidas.

Sendo assim, entendemos que, antes de retirar o objeto da criança autista, os educadores devem questionar-se a respeito da função dos mesmos e se realmente cumpre retirá-los. Portanto, antes de fazer oposição à persistência dos objetos autísticos, deve-se primeiro questionar se a supressão brutal dos mesmos não trará consequências nefastas para essas crianças e seus processos de aprendizagem e desenvolvimento.

\section{Relevância do trabalho colaborativo entre o AEE e a escola regular}

Acerca do trabalho colaborativo desenvolvido entre o AEE da instituição e a escola regular, consta no Projeto Político Pedagógico (GOIÂNIA, 2019) que a instituição tem um momento de devolutiva cujo objetivo é:

Indicar informações, estabelecer ações e es-
tratégias, que venham contribuir para o cres-
cimento, aprendizagem e desenvolvimento
das habilidades para melhor aproveitamento
do aluno na escola (GOIÂNIA, 2019, p. 118-119).

De acordo com o PPP da instituição esse é um momento em que estão presentes diversos profissionais que integram a equipe multidisciplinar da Associação Pestalozzi de Goiânia, entre eles destacam-se: "neuropedagogo, psicopedagogo, pedagogo, educador físico, musicoterapeuta, fonoaudiólogo, assistente social e coordenador pedagógico (GOIÂNIA, 2019, p. 119).

Ainda sobre a relação entre o AEE e a escola regular, a docente sublinha que há envolvimento efetivo entre essas duas instâncias, sobretudo no sentido de desenvolverem um planejamento conjunto, como podemos constatar no excerto abaixo:

Como as nossas crianças estão em escolas regulares da rede pública de ensino, nós sempre fazemos reunião com o professor, com o coordenador, com o cuidador e com o professor 
de apoio do aluno autista. É uma reunião que chamamos de devolutiva em que nós da instituição Pestalozzi dialogamos sobre a criança atendida no AEE. Nessa reunião nós fazemos um relatório de cada área em que a criança é atendida aqui no CAE Renascer. Os profissionais da instituição fazem um relatório de cada área e depois juntamos tudo num relatório único (Professora do AEE, informação verbal).

Sobre a periodicidade das devolutivas, a docente afirma que as reuniões são realizadas semestralmente com as escolas e os Centros Municipais de Educação Infantil (CMEIS), sendo esse o momento para apresentar os objetivos e os resultados alcançados, além de apresentar as estratégias utilizadas com cada criança, como vemos no excerto abaixo.

No dia da devolutiva só atendemos as escolas e CMEIS, não recebemos crianças é, e todo mês temos que fazer relatório. Mas a devolutiva, nós fazemos por semestre. Mas vamos supor que uma criança está com muita dificuldade lá, aí a gente prioriza essa criança na devolutiva. Nesse dia de devolutiva, apresentamos os objetivos, os avanços, as dificuldades da criança e aquilo que ela ainda não atingiu. Cada profissional que atende a criança sugere estratégias para promover a inclusão desse autista na sala regular. Na realidade, percebo que os professores das escolas regulares querem ouvir nossas orientações sobre como trabalhar com as dificuldades dessas crianças (Professora do $A E E$, informação verbal).

A docente (informação verbal) também ressalta que a parceria entre o AEE e a escola é de suma importância para que a criança autista seja efetivamente incluida no sistema regular de ensino. Ademais, destaca algumas orientações que são dadas aos professores em relação ao aluno autista.

Nós fazemos essa parceria para manter as nossas crianças na inclusão, permanecer na inclusão. Isso porque lá na rede eles têm o currículo, eles têm um programa lá que tem que ser cumprido. É naquele contexto que se trabalham os conteúdos acadêmicos, aqui não trabalhamos esses conteúdos. Aqui nós seguimos apenas o PPP. [...] Em relação ao aluno com TEA, tentamos orientar os professores sobre o fato de que essas crianças muitas vezes não têm noção de perigo e que podem se perder quando vão ao banheiro ou quando se deslocam na escola. Orientamos o professor para ficar atento, pois, muitas vezes, essa criança sai da sala de aula e não sabe voltar, principalmente no caso das escolas grandes e com um maior número de alunos (Professora do AEE, informação verbal).

É notório que os professores da Associação Pestalozzi de Goiânia-Unidade Renascer-seguem as orientações da Política Nacional de Educação Especial na Perspectiva da Educação Inclusiva (BRASIL, 2008b) e suas Diretrizes Operacionais (BRASIL, 2008a) quanto à organização e ao funcionamento do AEE, buscando dialogar com os professores da escola regular, construindo coletivamente um planejamento que atenda às necessidades e especificidades da criança que apresenta o autismo.

\subsection{O AEE e a familia dos estudantes com autismo}

Em suas narrativas, a docente (informação verbal) sublinha a importância do trabalho de parceria entre a familia e o AEE, como se pode observar no excerto abaixo.

Quando há reclamação da familia, a gente pega essa reclamação e trabalha em cima daquilo - dos relatos da família e da assistente social. [...] Nosso trabalho aqui é de orientação. As familias têm muitas dificuldades, e o método ajuda também as familias, antigamente, era muito difícil, as familias não podiam ir a um aniversário, não tinha convivência social por conta do comportamento do filho, a partir do momento que percebemos a importância do trabalho de parceria, as familias entenderam qual é o trabalho, qual é a comunicação, qual é essa linguagem para trabalhar com nossas crianças e elas fazem esse trabalho em casa é onde que favorece a qualidade de vida não só da criança, mas também da familia. [...] A gente fala pra eles, nós queremos que nossas crianças fiquem bem, não somente aqui na instituição, nós queremos que ele fique bem lá fora, que você aprenda lidar, aprenda trabalhar com seu filho principalmente lá fora, porque aqui dentro tem o nosso apoio, agora nas festas e nos eventos. A gente trabalha com as familias a não se preocupar com o outro, pois, às vezes, tem que inibir o comportamento, por isso aprendem dentro da instituição para trabalhar lá fora (Professora do AEE, informação verbal).

Dessa forma, conforme supracitado, é evidente a importância do trabalho colaborativo entre - AEE e a familia da criança autista. Acerca do exposto, Leon (2016) salienta que: 
[...] a parceria com os pais é crucial para que haja valorização, escuta às necessidades da familia e uma espécie de 'via de mão-dupla', no sentido de termos uma ação pedagógica junto aos pais, escutando-os e ensinando-os a lidar melhor com seus filhos (LEON, 2016, p. 12).

Confluindo, é importante destacar que os enunciados da docente estão em acordo com o que Silva e Mendes (2008) advogam. Em um estudo desenvolvido pelas pesquisadoras, "o respeito mútuo, comunicação, confiança, participação, amabilidade, sinceridade, seriedade e imparcialidade" (SILVA; MENDES, 2008, p. 233) foram características essenciais que emergiram nas respostas dos responsáveis participantes e que podem potencializar o trabalho colaborativo entre familia e escola.

Nesse caminho, entendemos que o envolvimento dos genitores e profissionais da educação como colaboradores frente à escolarização das crianças com autismo é essencial para garantir o êxito nos seus processos de aprendizagem e desenvolvimento (VARGAS; SCHMIDT, 2017).

\section{Considerações finais}

Importa antever que nossas análises foram fundamentadas no entendimento de uma educação inclusiva que visa à organização e/ou reestruturação do sistema educativo, e que considera as demandas, as necessidades e as particularidades das crianças. Também cumpre salientar que o presente trabalho teve por objetivo compreender como se dá o Atendimento Educacional Especializado (AEE) para alunos com Transtorno do Espectro do Autismo (TEA) na Associação Pestalozzi de Goiânia - Unidade Renascer.

Desse modo, levando-se em consideração a diversidade de manifestação de características comportamentais nas crianças com TEA, ao analisarmos a organização e funcionamento dos atendimentos, pudemos observar, por meio das falas da docente entrevistada e do Projeto Político Pedagógico da instituição, que os atendimentos individuais são fundamentais para o êxito nos processos de aprendizagem e desenvolvimento. Ademais, destaca-se que esses momentos devem ser sempre planejados a partir das necessidades desveladas pelas crianças em cada encontro.

No que concerne aos objetivos do Atendimento Educacional Especializado para alunos com autismo, percebemos que ele potencializa o desenvolvimento pleno e integral desses sujeitos, sendo de grande importância para o êxito nos processos de inclusão. No que tange ao processo de avaliação e ao plano de intervenção das crianças com TEA, constatamos que é importante um trabalho pormenorizado e individualizado, que engloba as especificidades de cada criança que apresenta o transtorno.

No que diz respeito às abordagens metodológicas utilizadas com alunos com autismo na sala do AEE, ficou evidente que o TEACCH tem sido a abordagem mais utilizada, sobretudo, por ser considerado pela docente um método mais acessivel e que, dessa maneira, preconiza um ensino estruturado. Ademais, ressalta-se que o desenvolvimento desse método na sala do AEE reflete diretamente no desenvolvimento da criança com TEA, proporcionando-lhe mais autonomia.

Pudemos constatar também que a linguagem é compreendida pela docente como um dos principais aspectos que impulsiona a desestruturação da criança com autismo. Desse modo, devido à sua relevância, é necessário que, no trabalho com as crianças com autismo, seja utilizada uma linguagem clara e objetiva, para que os comandos sejam compreendidos de forma holística.

A respeito da intervenção nos comportamentos autolesivos e nas estereotipias, pudemos notar que, de acordo com a professora, as crianças usam esses comportamentos com a finalidade de se comunicar ou até mesmo para se acalmar. Dessa forma, entende-se que esses comportamentos devem ser modificados ou extintos somente quando se põe em risco a integridade física da própria criança e de terceiros, pois as crianças com autismo, na maioria das vezes, não têm noção das consequências das suas ações.

No que se refere às fixações por objetos que lhes despertam interesse, essa é uma característica presente no autismo que tem implicações para 
a aprendizagem e desenvolvimento da criança com TEA, pois pode ocasionar a desestruturação da criança, até mesmo fora dos ambientes escolares e, portanto, causar-lhe muito sofrimento. Desse modo, constatamos o quão importante é trabalhar limitando o acesso e o tempo de uso da criança com o objeto de fixação e, desse modo, desenvolver trabalhos que possibilitem que 0 referido objeto se torne comum para ela.

Em relação à relevância do trabalho de parceria entre o AEE e a escola regular, ficou elucidado que não existe troca entre os docentes durante a realização dos planejamentos. Contudo, sabemos o quanto essa parceria pode implicar positivamente na aprendizagem dessas crianças, sendo assim, salientamos que o planejamento conjunto e o trabalho colaborativo são muito profícuos para se delinear objetivos e práticas pedagógicas calcadas na individualidade do sujeito.

Compreendemos, portanto, que a relação entre os professores do AEE e do ensino regular não podem restringir-se apenas aos momentos de devolutivas, pois o planejamento é um momento privilegiado para potencializar diálogos acerca das demandas de aprendizagem da criança, ou seja, sobre aquilo que a criança está alcançando e sobre o que ainda é necessário avançar.

Sobre a relevância do trabalho de parceria entre o AEE e a familia, ficou evidente que a parceria entre ambos é essencial para o desenvolvimento da criança com TEA, sobretudo, para melhorar a qualidade de vida dos mesmos, além de tornar a vida dos pais mais fácil em diversos contextos.

A partir de nossas análises, pudemos considerar que a docente possui um amplo conhecimento acerca do AEE para crianças com autismo, e que é importante o trabalho desenvolvido pela mesma na sala de Atendimento Educacional Especializado. Contudo, esse é um trabalho muito complexo, pois as crianças com autismo demandam um trabalho minucioso, fazendo necessário um olhar diferenciado com planejamentos coletivos por parte dos profissionais envolvidos.

Por fim, entendemos que a parceria com os pais, o trabalho colaborativo e de orientação com as famílias é, indubitavelmente, um dos pontos mais relevantes do trabalho da docente no $\mathrm{AEE}$ da referida instituição. Ademais, desvela-se, por meio da pesquisa empreendida, que é preciso um trabalho colaborativo de toda uma equipe multiprofissional, para que a criança com TEA possa romper as barreiras que a impede de aprender, de se desenvolver, de construir sua autonomia e de fato ser incluído não só na escola, mas em todas as esferas da sociedade.

\section{Referências}

ATTWOOD, Tony. Tudo sobre a sindrome de Asperger. Lisboa: Babel, 2010.

Bardin, Laurence. Análise de conteúdo. São Paulo: Edições 70, 2011.

BRASIL, Ministério da Educação. Saberes e práticas da inclusão: dificuldades acentuadas de aprendizagem, autismo. Brasilia, DF: MEC, 2004.

BRASIL. Decreto n 7.611, de 17 novembro de 2011. Dispõe sobre a educação especial, o atendimento educacional especializado e dá outras providências. Brasilia, DF, 17 nov. 2011. Disponivel em: http://www. planalto.gov.br/ccivil_03/_ato2011-2014/2011/decreto/d7611.htm Acesso em: 17 set. 2021.

BRASIL. Ministério da Educação. Diretrizes operacionais da educação especial para o atendimento educacional especializado (AEE) na educação básica. Brasilia, DF: MEC/SEESP, 2008a.

BRASIL. Ministério da Educação. Política Nacional de Educação Especial na perspectiva da Educação Inclusiva. Brasilia, DF: MEC/SEESP, 2008b. Disponível em: http://portal.mec.gov.br/arquivos/pdf/politicaeducespecial.pdf. Acesso em: 10 set. 2021.

CRUZ, Talita. Autismo e inclusão: experiências no ensino regular. Jundiai: Paco Editorial, 2014.

FONSECA, Maria Elisa Granchi; CIOLA, Juliana de Cássia Baptistella. Vejo e aprendo. Fundamentos do Programa TEACCH: o ensino estruturado para pessoas com autismo. 2. ed. Ribeirão Preto, SP: Book T30y, 2014.

GOIÂNIA. Secretaria Municipal de Educação. Projeto Político Pedagógico da Associação Pestalozzi de Goiânia - Unidade Renascer: Centro de Atendimento Especializado Renascer. Goiânia: Secretaria Municipal de Educação, 2019.

LEON, Viviane Costa de. Práticas baseadas em experiências para aplicação do TEACCH nos Transtornos do Espectro do Autismo. São Paulo: Ed. Memmon, 2016.

MALEVAL, Jean-Claude. O autista e a sua voz. São Paulo: Blucher, 2017.

NUNES, Débora Regina de Paula. Comunicação alternativa e ampliada para pessoas com autismo. In: SCHMIDT, Carlo (org.). Autismo, educação e transdisciplinaridade. Campinas: Papirus, 2013. p. 145-164. 
OLIVEIRA, Ana Flávia Teodoro de Mendonça; Costa, Maria Lúcia Gurgel da; SILVA, Katleen Côrtes da. Contribuições para se compreender a linguagem das pessoas com transtorno do Espectro do Autismo (TEA): uma análise da autobiografia de Nicolas Brito. Revista Educação Especial em debate, Vitória/ES, v. 4, p. 40-58, 2019. Disponivel em: https://periodicos.ufes.br/reed/ article/view/26518. Acesso em: 29 set. 2021

SILVA, Aline Maira da; MENDES, Enicéia Gonçalves Familia de crianças com deficiência e profissionais: componentes da parceria colaborativa na escola. Revista Brasileira de Educação Especial, Bauru/SP, v. 14, p. 217-234, 2008. Disponivel em: https://www.scielo. $\mathrm{br} / \mathrm{j} / \mathrm{rbee} / \mathrm{a} / X C s M X P G w S n d b Z Y p r k d j R f m n /$ fforma$\mathrm{t}=$ pdf\&lang=pt. Acesso em: 8 set. 2021

SILVA FILHO, Raimundo. B. DA; BARBOSA, Elma S. C. Educação Especial: da prática pedagógica à perspectiva da inclusão. Educação Por Escrito, Porto Alegre/ RS, v. 6, n. 2, p. 353-368, 17 ago. 2015. Disponivel em: https://doi.org/10.15448/2179-8435.2015.2.20575 Acesso em: 12 nov. 2021

SOUZA, Renata Ferreira de; NUNES, Débora Regina de Paula. Transtornos do processamento sensorial no autismo: algumas considerações. Revista Educação Especial, Santa Maria, RS, v. 32, p. 1-17, 2019. Disponivel em: https://www.redalyc.org/jatsRepo/3131/313158902022/313158902022.pdf. Acesso em: 30 set. 2021.

TAMMET, Daniel. Nascido em um dia azul: por dentro da mente de um autista extraordinário. Rio de Janeiro: Intrinseca, 2007

VARGAS, Rosanita Moschini; SCHMIDT, Carlo. Envolvimento parental e a inclusão de alunos com autismo. Acta Scientiarum. Education, Maringá, PR, v. 39, n. 2, p. 207-217, 2017. Disponivel em: https://doi.org/10.4025/ actascieduc.v39i2.26423. Acesso em: 20 set. 2021.

WILLIAMS, Chris; WRIGH, Barry. Convivendo com autismo e sindrome de Asperger: estratégias práticas para pais e profissionais. São Paulo: M. Books do Brasil, 2008.

WILLIAMS, Donna. Meu mundo misterioso: testemunho excepcional de uma jovem autista. Tradução de Terezinha Braga Santos. Brasilia: Thesaurus, 2012.

\section{Márcia Sacramento Rocha}

Licenciada em Pedagogia pela Universidade Federal de Goiás Universidade Federal de Goiás (UFG), em Goiânia, Goiás, Brasil; mestranda em Antropologia Social pelo PPGAS em mesma instituição.

\section{Ana Flávia Teodoro de Mendonça Oliveira}

Doutora e mestra em Educação pela Universidade Federal de Pernambuco (UFPE); graduada em Fonoaudiologia pela Pontificia Universidade Católica de Goiás (PUC GO); professora do magistério superior na Faculdade de Educação da Universidade Federal de Goiás (UFG), em Goiânia, Goiás, Brasil. Coordenadora do Núcleo de Acessibilidade na FE/UFG.

\section{Michell Pedruzzi Mendes Araújo}

Doutor e mestre em Educação pela Universidade Federal do Espirito Santo (Ufes); licenciado em Pedagogia pelo Centro Universitário de Maringá-PR (Cesumar) e em Ciências Biológicas pela Universidade Federal do Espirito Santo (Ufes); professor do magistério superior na Faculdade de Educação da Universidade Federal de Goiás (UFG), em Goiânia, Goiás, Brasil.

\section{Endereços para correspondência}

\section{Márcia Sacramento Rocha}

Universidade Federal de Goiás

Campus Samambaia

R. Jacarandá

Chácaras Califórnia, 74045-155

Goiânia, GO, Brasil

\section{Ana Flávia Teodoro de Mendonça Oliveira}

Universidade Federal de Goiás

Campus Colemar Natal e Silva

R. 235, 307 - Setor Leste Universitário

74605-050

Goiânia, GO, Brasil

Michell Pedruzzi Mendes Araújo

Universidade Federal de Goiás

Campus Colemar Natal e Silva

R. 235, 307 - Setor Leste Universitário

74605-050

Goiânia, GO, Brasil

Os textos deste artigo foram revisados pela Poá Comunicação e submetidos para validação do(s) autor(es) antes da publicação. 